\title{
The Application of Multimedia Technology in the Teaching of Higher Agricultural Colleges
}

\author{
Cao Liying, Yu Helong, Chen Guifen, Sun Peng \\ College of Information and Technology Science, Jilin Agricultural University, China, 130118 \\ E-mail: caoliying99@163.com
}

Keywords: modern educational technology; initiative; student; teacher; learning interest

\begin{abstract}
In the past, modern history, each item of the progress of the information technology, has greatly influenced the education. On the one hand is the traditional education is facing severe challenges, on the other hand, also created a good opportunity for the further development of education. However, the realistic situation is not so optimistic as people think, this is because the means and methods of many teachers can't effectively using this new technology in the classroom teaching in the classroom teaching to achieve high efficiency, the reason is very complex, but the most important reason is the information technology and classroom teaching fails to form organic the overall. Therefore, to change this situation, we must take the necessary steps, so that the information technology plays an important role in the classroom teaching.
\end{abstract}

\section{Introduction}

Educational technology is a design, development, utilization, management and evaluation of the theory and practice of processes and resources for learning. Modern educational technology is the use of modern education theories and modern information technology, through the design, the teaching process and teaching resources development, utilization, evaluation and management, theory and practice to achieve teaching optimization. Modern education technology has the following characteristics: focus and is based on the students' learning, fully reflect the students' subject status. Therefore, it is the study of the learning process and learning resources; the research contents include the "learning" and "learning resources" design, development, utilization, management and evaluation of five aspects; the dual attributes of theory and practice; educational technology is a product of advanced education thought and the teaching of advanced technology. Combined with modern educational technology, with the development of modern science and technology and the modern education thought and constantly updated and enriched the connotation of its own.

\section{The necessity of application of computer information technology in Teaching}

Multimedia teaching is the modern education the most advanced teaching method. For the traditional teaching, it is difficult to express, for students to understand abstract content, complex process of change, fine structure, multimedia through animation, local amplification, presentations and other means can be solved, it breaks the "chalk and blackboard, the traditional teaching method of teachers What I say goes.", not only to play a multiplier effect in the process of teaching, but also help to improve learning interest and analysis, students' ability to solve problems, greatly improve the teaching quality and efficiency.

The use of multimedia, the curriculum form becomes diverse, easy to stimulate student interest in learning.

Educator Shinseki said: "no interest, and was compelled to carry out the study, would stifle the will of their mastery of knowledge." Stimulate the interest of students in teaching, to attract the attention of students, can be used by means of computer multimedia. Teachers in teaching according to the text, use the multimedia show, play some related picture, animation, video, audio, and perceptual materials these visual image, attractive, often can mobilize the enthusiasm of students. 
The use of multimedia, enhanced the intuitive teaching, help students to understand the content of teaching.

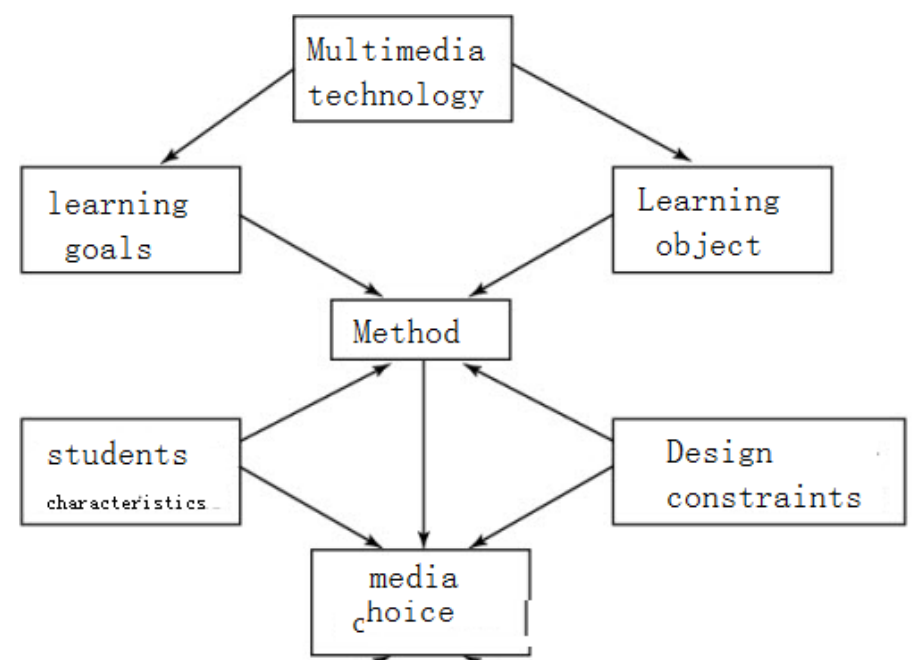

Fig 1 the structure of multimedia information technology

Practice has proved, AIDS or objects are more persuasive than language and real sense. In the information technology teaching, if teachers can flexibly by visual means of teaching, not only make the student impression on the knowledge is profound, but also better able to attract the attention of students, stimulate students desire for knowledge. Although teachers can set a variety of students to read aloud the form to stimulate students' reading pleasure, but if more points through the modern computer multimedia audio and video to use descriptive scene representation language, can make the concrete content of the text, image, heard many media demonstration of reading, students naturally infected, influence, and it is easy to understand, accept the contents of the text.

The use of multimedia teaching cans effectively the use of media teaching technology in teaching practice.

Use of multimedia teaching means to organize the teaching and the use of media teaching techniques in the teaching practice, has a profound effect on the teaching process, promote the organic combination of theory teaching and practice teaching. The students master the basic concepts, scientific knowledge of the principles, aims to put knowledge into practice. An important task of modern education is professional and technical personnel training application, tens of millions of skilled, the training of personnel must have the necessary theoretical knowledge and strong practical ability. This requires that in the process of teaching is to highlight the practice of teaching, but also to ensure the learned "must", "enough" theory of knowledge. In the traditional teaching mode, the teaching means backward, theory teaching and practice teaching are separated, the classroom teacher taught theory, students find it difficult to intuitively through experimental timely digest theory of knowledge. The multimedia technology to the teaching theory and practice organically fuses in together, teachers use multimedia technology can explain the theory knowledge, demonstration experiment steps, guide students to learn, even let the students themselves simulation experiment, so that students can learn to "necessary" skills, theoretical knowledge and get "enough", master the practical operation ability.

The above is my understanding of multimedia teaching, although effective multimedia teaching to improve teaching efficiency and teaching quality, but also should pay attention to completely replace the traditional teaching methods can't multimedia teaching means, and should be combined with traditional teaching method, and compared with professional teachers, multimedia teaching is still in the secondary status in the teaching, even if a multimedia completed many humanly impossible task, all work cannot replace the role of teachers, the teaching process still needs teachers to organize the implementation, therefore, teachers should carefully through the careful design of teaching, choose the most suitable teaching media. In the process of teaching, teachers should fully play a leading role in modern education, multimedia will inject new vitality. 


\section{Problems and Countermeasures of computer information technology application in Teaching}

At present, the information technology to promote the teaching reform, the school the use of information technology to the teaching of all subjects, however, information technology application and practice in the process of teaching, many schools generally exist some problems on the understanding of information technology in the application in the teaching and practice. In the development process to some extent hindered the teaching reform of these problems, the application of information technology in teaching deviate from the correct direction. Therefore, there exist the following errors and countermeasures.

(1) Using a multimedia show much teaching, teaching center offset

In teaching, some teachers think in the multimedia teaching in the new curriculum reform is the universal technology teaching in class from first to last, are the use of multimedia, and on the other a contemptuous disregard of conventional media. In some open classes, and we even saw some teachers purely to multimedia blackboard and wall charts and experiment, the after modern meaning is good, but everything has its director, also has its short. In general, the use of multimedia teaching will be abstract object specific, micro and macro objects, are of some help to teachers in the teaching focus and difficulty, but the multimedia display much can cause negative effect.

(2) The use of multimedia courseware, easy to neglect the students cognitive law

Some teachers at the time of making courseware blindly pursue multimedia effects, excessive use of sound, pictures, animation to show the teaching content, backfired, but students are distracted, deviated from the theme of knowledge transfer. Some teachers regardless of subject and the knowledge of special, will be the use of multimedia teaching methods, neglect the student's cognition rule, the formula derivation, examples of calculus once displayed, so no leave the students thinking and digestion time, nor the students' logical reasoning ability training. We use the courseware in class are in advance according to the teaching requirements and design, and now most of the courseware development neglected this point, only the pursuit of visual and vivid, forget the initiative as the subject of the students. Emphasize the teachers "teach" and ignore the "learning" of the students, all the teaching design theory is mainly about how to "teach" and "how to learn, rarely" problem, in accordance with this theory to the design of classroom teaching software. Students to participate in teaching activities less chance, most in the state of passive acceptance, the initiative, the enthusiasm of the students is difficult to play, not conducive to the cultivation of creative talents. It is easy to go into a "human pouring + machine" of the new classroom teaching. Teachers have also been finalized courseware effect plot, completely surrounds the courseware lectures, the lack of classroom teaching in the most splendid "improvisation". The original "courseware assistant teacher" into "the teacher assisted courseware".

\section{Conclusion}

Not all of the teaching content should be the use of modern means of teaching, chalk and blackboard cannot completely abandon. Some teachers think that using PowerPoint to do slide, can input a large amount of text, animation, sound effects, good! At the same time, also need not write, it is convenient. In fact, this idea is not correct, the teacher's blackboard writing has its own one's own knack in, is unable to replace other means, it should be, because of course vary because of different, can't follow the same pattern.

To make a long story short, the appropriate use of modern teaching methods to teaching, makes the task easy, from abstract to concrete, make the teaching image, can fully mobilize students' thinking, give full play to the role of vision and perception, the students in the colorful world of Chinese, let the students relaxed, happy, active, effective learning, in order to optimize classroom teaching, improve the quality of teaching, to improve students' comprehensive quality objective. 


\section{References}

[1] Hu Li. Study and modern education technology. Popular Science Press.2003

[2] South China Agricultural. Thinking deeply the development of China's education. Chinese audio-visual education $(1997,12)$

[3] Sun Changda. The theory and method of multimedia teaching. China Distance Education (.2002 7)

[4] Chen Mengxian. Educational technical training, improve the teachers' information literacy. Higher education exploration.2003, (3)

[5] Zou Ming, the application of information technology in Chinese teaching of high school education in Hunan "," 2001 December Edition

[6] Zhang Xin, thinking of modern technology of education, "people's education", in December 5, 2003 Fourth Edition

[7] He Kekang, Li Kedong: "computer application foundation" (the secondary normal school textbooks), Beijing, Beijing Normal University press, 1999

[8] Wang Zhiwen: "design" multimedia aided teaching and software of computer, Zhejiang science and Technology Press, 2000 